\title{
BMJ Open Rate of venous thromboembolism among surgical patients in Australian hospitals: a multicentre retrospective cohort study
}

\author{
Hassan Assareh, ${ }^{1,2}$ Jack Chen, ${ }^{1}$ Lixin Ou, ${ }^{1}$ Stephanie J Hollis, ${ }^{1}$ Kenneth Hillman, ${ }^{1}$ \\ Arthas Flabouris ${ }^{3}$
}

To cite: Assareh $\mathrm{H}$, Chen J, $\mathrm{Ou} \mathrm{L}$, et al. Rate of venous thromboembolism among surgical patients in Australian hospitals: a multicentre retrospective cohort study. BMJ Open 2014;4:e005502. doi:10.1136/bmjopen-2014005502

- Prepublication history and additional material is available. To view please visit the journal (http://dx.doi.org/ 10.1136/bmjopen-2014005502).

Received 22 April 2014 Revised 25 August 2014 Accepted 26 August 2014

CrossMark

For numbered affiliations see end of article.

Correspondence to Dr Hassan Assareh; h.assareh@unsw.edu.au

\begin{abstract}
Objectives: Despite the burden of venous thromboembolism (VTE) among surgical patients on health systems in Australia, data on VTE incidence and its variation within Australia are lacking. We aim to explore VTE and subsequent mortality rates, trends and variations across Australian acute public hospitals.
\end{abstract}

Setting: A large retrospective cohort study using all elective surgical patients in 82 acute public hospitals during 2002-2009 in New South Wales, Australia.

Participants: Patients underwent elective surgery within 2 days of admission, aged between 18 and 90 years, and who were not transferred to another acute care facility; 4362624 patients were included.

Outcome measures: VTE incidents were identified by secondary diagnostic codes. Poisson mixed models were used to derive adjusted incidence rates and rate ratios (IRR).

Results: 2/1000 patients developed postoperative VTE. VTE increased by $30 \%$ (IRR=1.30, $\mathrm{Cl} 1.19$ to 1.42) over the study period. Differences in the VTE rates, trends between hospital peer groups and between hospitals with the highest and those with the lowest rates were significant (between-hospital variation). Smaller hospitals, accommodated in two peer groups, had the lowest overall VTE rates (IRR=0.56:0.33 to 0.95; IRR=0.37:0.23 to 0.61) and exhibited a greater increase ( $64 \%$ and $237 \%$ vs $19 \%$ ) overtime and greater between-hospital variations compared to larger hospitals (IRR=8.64:6.23 to 11.98; IRR=8.92:5.49 to 14.49 vs IRR=3.70:3.32 to 4.12 ). Mortality among patients with postoperative VTE was $8 \%$ and remained stable overtime. No differences in post-VTE death rates and trends were seen between hospital groups; however, larger hospitals exhibited less between-hospital variations (IRR=1.78:1.30 to 2.44) compared to small hospitals (IRR>23). Hospitals performed differently in prevention versus treatment of postoperative VTE.

Conclusions: VTE incidence is increasing and there is large variation between-hospital and within-hospital peer groups suggesting a varied compliance with VTE preventative strategies and the potential for targeted interventions and quality improvement opportunities.

\section{Strengths and limitations of this study}

- This study benefited from a large cohort design within the largest health jurisdiction in Australia.

- Employment of standardised and broadly-applied venous thromboembolism (VTE) measures facilitated local and international comparisons and benchmarking.

- Demonstration of trends and variations in VTE measures reflected effectiveness of systematic interventions and revealed opportunities for further improvement and actions at local and regional levels.

- This study was limited to VTE incidence among elective surgical patients. Analysis of all patient populations may provide addition insight.

- The obtained rates may have underestimated due to possible coding discrepancies.

\section{INTRODUCTION}

Venous thromboembolism (VTE), comprised of deep-vein thrombosis (DVT) and pulmonary embolism (PE), can cause long-term comorbidities or death ${ }^{12}$ and incur a significant financial burden on healthcare systems. ${ }^{3}{ }^{4}$ It accounts for nearly $10 \%$ of all deaths in $\mathrm{USA}^{56}$ and Australian hospitals, ${ }^{78}$ and is among the top five most common causes of hospital-related deaths in both countries. ${ }^{3}{ }^{9}$ However, VTE is also the most common preventable cause of hospital deaths. ${ }^{10-13}$ A significant decrease in VTE incidents has been reported where efficacious and cost-effective treatments (ie, pharmacological and mechanical prophylaxis) were used for medical as well as surgical patients. ${ }^{1}{ }^{12}$ 14-19 Accordingly, several evidence-based VTE prevention and treatment guidelines were developed ${ }^{19}{ }^{20}$ and related measures were adopted among quality of care indices for accreditation, quality improvement and benchmarking purposes. $^{21-23}$ 
The Agency for Healthcare Research and Quality (AHRQ) listed postoperative VTE complication (VTE incidence following surgery) and subsequent death as a component of failure-to-rescue (FTR) among patient safety indicators (PSI \#12 and PSI \#4-2, respectively), which are routinely being monitored and publically reported..$^{23} 24$ Reports showed that postoperative VTE incidence rates have nearly halved in USA hospitals in recent years ${ }^{24} 25$ and post-VTE mortality rates declined by a third within a decade since the mid-90s. ${ }^{26}$ These rate decreases may be, in part, due to the implementation of postoperative VTE prevention protocols, ${ }^{27}$ however, substantial variation in postoperative VTE incidence rates was also evident among US hospitals. ${ }^{25}$ Although patients' case mix and surgery types may play a role in such differences, ${ }^{6}{ }^{28} 29$ the variation of VTE incidence among the same type of hospitals overtime and within the group may reflect the success of quality improvement interventions and demonstrate the potential for further development. ${ }^{30} 31$

Few Australian studies have reported VTE incidence, ${ }^{3} 832$ and the measures of VTE used in these studies varied making comparison difficult. Consequently, we employed the internationally-recognised AHRQ measures for postoperative VTE, and subsequent mortality, to explore the trend of the incidence rates and their variations among admitted surgical patients in acute public hospitals across New South Wales (NSW), Australia (2002-2009).

\section{METHODS}

Data source and study population

NSW is the largest health jurisdiction in Australia with approximately 497 healthcare facilities and a population of over seven million people. We used records from the NSW Admitted Patient Data Collection (APDC) database, which includes all admitted patient services provided by NSW public and private healthcare facilities. The APDC includes information on patient demographics, medical conditions and procedures, hospital characteristics, and separations (discharges, transfers and deaths) from all public and private hospitals (as well as day procedure centres) in NSW. The medical records for each episode of care in the APDC were assigned with codes based on the International Statistical Classification of Diseases and Related Health Problems, Tenth Revision, Australian Modification (ICD-10-AM) 4th edition. ${ }^{33}$ Of admissions at 497 healthcare facilities across NSW between 1 January 2002 to 31 December 2009, we included all 82 NSW acute public hospitals (9221 128 admissions; 57.4\%) in our study. Two children's hospitals and one other hospital (data was unavailable) were excluded. We restricted our study to only elective surgical patients and applied the same AHRQ inclusion criteria ${ }^{23}$ for patients who had elective surgery within 2 days of admission, those criteria being: patients should be aged between 18 and 90 years (inclusive), and should not have been transferred to another acute care facility (4 362624 episodes $(47.3 \%)$ ).

\section{Measures and covariates}

Of surgical patients who met AHRQ inclusion criteria (patients at risk), those who developed VTE were identified by secondary diagnostic codes (ICD-10-AM) translated from the AHRQ definition ICD, Ninth Revision, Clinical Modification (ICD-9-CM) by Victorian Government Health Information. ${ }^{34}$ The outcome measure was termed 'postoperative VTE', proposed by the Australian version of PSIs (AusPSI) ${ }^{35}$ instead of the 'perioperative VTE' term suggested by AHRQ. ${ }^{23}$ We used the 'postoperative VTE' term since employment of inclusion criteria (undergoing surgery within 2 days of admission and secondary diagnosis of VTE) minimised likelihood of VTE presence on admission or VTE occurance prior to surgery. In combination with discharge status, patients' post-VTE outcomes were categorised as survival or death. VTE and related death rates were presented as incidences per 1000 admissions within each year between 2002 and 2009, inclusively.

Two sets of patient-related and hospital-related covariates were considered. Patient demographic variables included age, gender, country of birth, marital status, patient socioeconomic status and principle diagnostic disease groups (the 10 most common) within the study population. We utilised a postcode-level advantage and disadvantage index of Socio-Economic Indices for Areas (SEIFA) with the lower values indicating more disadvantaged areas. ${ }^{36}$ SEIFA scores were categorised into four classes (1st quartile $(\mathrm{Q} 1)=$ most disadvantaged areas and 4 th quartile $(\mathrm{Q} 4)=$ most advantaged areas). The disease groups were identified using principle diagnostic codes (ICD-10-AM) at admissions through the methodology developed by Quan et $a l^{37}$ Using relevant procedure codes from ICD-10-AM (see online supplementary appendix 1), we defined six major surgical procedures including coronary-artery bypass graft, abdominal aortic aneurysm (AAA) repair, total hip replacement, total knee replacement, cholecystectomy and other surgical procedures.

Hospital covariates included the local health district (metropolitan, rural and regional NSW) and peer group (A1: principal referral group, usually teaching hospitals; A3: ungrouped acute; B: major metropolitan and nonmetropolitan; C1: district group 1; and, C2: district group 2). Hospital peer groups contained similar type and sized hospitals, ranging from those treating more than 25000 acute case-mix weighted separations per annum in principal referral groups through to treating $2000^{+}$(but less than 5000) acute case-mix weighted separations per annum in district group $2 .{ }^{38}$

\section{Statistical analysis}

We employed Poisson mixed models to evaluate adjusted incidence rates and rate ratios for study outcomes after including all patients and hospital-related characteristics. A random intercept term was utilised to incorporate any clustering effect at hospital-level. To investigate the temporal behaviour of the outcomes, calendar years were entered into the model as indicator variables, with 2002 
as the reference year. A model with the year as a continuous variable was also examined for linear trends. We derived hospital peer group and surgery type trends using interaction effects (year and hospital peer group; year and surgery type) in separate models. Adjusted incidence rates for specific years were derived by multiplying yearly-adjusted risk ratios to the crude risks observed in the reference year.

We initially examined the Elixhauser and the Charlson Index comorbidities based on the ICD-10 coding scheme ${ }^{37}$ however, we did not include either of them in the models given an unexpected drop in the comorbidity index among our study population in recent years (see online supplementary appendix 2) and also recent reports that these indices may introduce misleading results possibly due to geographical variations and biases in the coding. ${ }^{39-41}$ To study the variation of outcomes across hospitals within each hospital group, hospitalspecific random intercept components were extracted from Poisson mixed models constructed for each hospital group, then ranked and categorised into five classes at $20 \%$ incremental quintiles. To obtain adjusted differences between those with the highest and those with the lowest VTE incidence, the adjusted classes were entered into a Poisson model including patient characteristics covariates. We used Pearson correlation to assess the association of hospital performances between VTE and post-VTE deaths, based on the hospital-specific random intercepts. All analyses were performed in $\mathrm{R}$ package V.3.0.0 $0^{42}$ and Stata V.11.0. ${ }^{43}$

\section{RESULT}

Table 1 summarised the study population by outcomes across hospital and patient characteristics and related statistics. Of the 4223317 (45.8\% of all admissions with no missing information) elective surgical admissions during 2002-2009 with a median length of stay of 1 day (the Q1 and the third quartiles (Q3) equal to 1 day), 8451 patients developed either DVT or PE after surgery, resulting in an incidence rate of 2/1000 surgical patients with a median length of stay of 11 days $(\mathrm{Q} 1=6$ and $\mathrm{Q} 3=21$ days). Among them, 673 (8\%) died prior to discharge with a median length of stay of 11 days $(\mathrm{Q} 1=4$ and $\mathrm{Q} 3=22$ days); 79.6/1000 patients with postoperative VTE. Compared to women, men tended to have a lower risk of postoperative VTE (incidence rate ratio (IRR) $=0.91)$; however, they were more likely to die $($ IRR $=1.19)$ following a VTE. Older patients were exposed to higher risks of VTE and death after surgery. Married patients and those who were born in Europe (except the UK), Asia and North Africa experienced a lower risk of postoperative VTE compared to their counterparts but a similar risk of post-VTE death.

Patients admitted with malignancy and congestive heart failure had the highest VTE and hospital mortality rates. Patients who underwent total knee replacement, AAA repair and total hip replacement surgeries had higher risk of VTE, respectively; however, post-VTE mortality was lower among orthopaedic surgical patients compared to other procedures. Higher socioeconomic status (quartiles of SEIFA) of patients was associated with a lower risk of VTE. There was no difference in mortality for patients residing in advantaged and disadvantaged areas. Patients from principal referral hospitals were more likely to acquire VTE in comparison to the patients from district hospitals (IRR $=0.56$ and 0.37 for group 1 and 2 hospitals respectively). No differences in outcomes were observed between metropolitan and non-metropolitan hospitals.

Postoperative VTE incidence rates significantly increased over the study period by $30 \%$, from $1.77 / 1000$ patients in 2002 to 2.30 in 2009 (figure 1). Despite some fluctuation, all hospital peer groups exhibited similar increasing trends in postoperative VTE incidence over the study period after adjustment for patient demographics (figure 2), ranging from 19\% (2.58 vs 2.17) in principal referral hospitals to $237 \%$ (1.21 vs 0.36 ) in district group 2. Surgery-specific VTE rates for the five procedures exhibited high fluctuations and insignificant trends, whereas the other surgery group showed a steady increasing trend of $38 \%$ (3.01 vs 2.18) over the study period (figure 3). Post-VTE mortality fluctuated between 68 and 97 cases per 1000 patients over the study period with no significant change after adjusting for confounders overall (figure 1) and at hospital peer group level (figure 2). Mortality tended to be stable across hospital peer groups as between-group variation of mortality reduced over the study period. No surgery-specific trend analysis was conducted due to small number of post-DVT deaths per annum.

The incidence rate ratios between those hospitals with the lowest, and those with the highest rate, was larger in VTE related mortality than in VTE and varied across hospital peer group (table 2). For VTE, the difference in rate is less than fourfold in the principal referral and major peer groups (include large hospitals) but at least eightfold in district peer groups (include small hospitals). Similarly, the difference in rate is larger in district group 1 and 2 (IRR=23 and 38) compared to principal referral $(\mathrm{IRR}=1.7)$ and major metropolitan/non-metropolitan hospitals $(I R R=15)$ for VTE related deaths. The close to significant negative correlation $(-0.45, \mathrm{p}$ value $=0.057)$ for principal referral hospitals implied that hospitals with the highest postoperative VTE rate tended to have a lower rate of subsequent death. In contrast, within district group 2 (0.41), hospitals with higher VTE rates tended to also have the highest post-VTE death rates. There were no such associations within other peer groups.

\section{DISCUSSION}

In this large cohort study of elective surgical patients from all NSW acute public hospitals over an 8-year period, we found the incidence of VTE to be 2 of 1000 elective surgical admissions, and VTE-associated 
Table 1 Study population, IR and adjusted IRR of surgical patients who developed VTE and died, stratified by patient and hospital characteristics

\begin{tabular}{|c|c|c|c|c|c|c|c|}
\hline \multirow[b]{2}{*}{ Characteristics } & \multirow{2}{*}{$\begin{array}{l}\text { Surgical } \\
\text { patients n (\%) }\end{array}$} & \multicolumn{3}{|l|}{ VTE } & \multicolumn{3}{|c|}{ VTE-associated death } \\
\hline & & Frequency (\%) & IR & IRR (95\% Cl) & Frequency (\%) & IR & IRR (95\% CI) \\
\hline \multicolumn{8}{|l|}{ Sex } \\
\hline Female & 2280384 (54.00) & $4626(54.74)$ & 2.03 & 1.00 & 330 (49.03) & 71.34 & 1.00 \\
\hline Male & 1942933 (46.00) & 3825 (45.26) & 1.97 & $0.90(0.86 \text { to } 0.94)^{*}$ & $343(50.97)$ & 89.67 & $1.19(1.02$ to 1.40$) \dagger$ \\
\hline \multicolumn{8}{|l|}{ Age (years) } \\
\hline$\geq 18$ and $<35$ & 738382 (17.48) & $487(5.76)$ & 0.66 & $0.21(0.19 \text { to } 0.23)^{\star}$ & $11(1.63)$ & 22.59 & $0.20(0.11 \text { to } 0.37)^{*}$ \\
\hline$\geq 35$ and $<55$ & 1013921 (24.01) & $1308(15.48)$ & 1.29 & $0.42(0.40 \text { to } 0.45)^{*}$ & $82(12.18)$ & 62.69 & $0.58(0.45 \text { to } 0.74)^{*}$ \\
\hline$\geq 55$ and $<75$ & 1595024 (37.77) & $3538(41.86)$ & 2.22 & $0.66(0.63 \text { to } 0.70)^{*}$ & $290(43.09)$ & 81.97 & 0.85 (0.72 to 1.01$)$ \\
\hline$\geq 75$ and $<90$ & $875990(20.74)$ & 3118 (36.90) & 3.56 & 1.00 & $290(43.09)$ & 93.01 & 1.00 \\
\hline \multicolumn{8}{|l|}{ Marital status } \\
\hline Married & 2548508 (60.34) & 4667 (55.22) & 1.83 & 1.00 & $381(56.61)$ & 81.64 & 1.00 \\
\hline Single & 1674809 (39.66) & $3784(44.78)$ & 2.26 & $1.16(1.11 \text { to } 1.21)^{*}$ & 292 (43.39) & 77.17 & $1.01(0.86$ to 1.18$)$ \\
\hline \multicolumn{8}{|l|}{ Country of birth } \\
\hline Australia and New Zealand & 2839135 (67.23) & 5858 (69.32) & 2.06 & 1.00 & $479(71.17)$ & 81.77 & 1.00 \\
\hline UK, US and Canada & $239088(5.66)$ & $645(7.63)$ & 2.70 & $1.06(0.97$ to 1.15$)$ & $53(7.88)$ & 82.17 & $0.95(0.72$ to 1.27$)$ \\
\hline Non-English Europe & 447239 (10.59) & $1046(12.38)$ & 2.34 & $0.74(0.69 \text { to } 0.80)^{*}$ & $80(11.89)$ & 76.48 & 0.91 (0.71 to 1.16$)$ \\
\hline North Africa & $130938(3.10)$ & $139(1.64)$ & 1.06 & $0.47(0.40 \text { to } 0.56)^{*}$ & $9(1.34)$ & 64.75 & $0.87(0.45$ to 1.70$)$ \\
\hline Asia & $179725(4.26)$ & $193(2.28)$ & 1.07 & $0.45(0.39 \text { to } 0.52)^{*}$ & $16(2.38)$ & 82.90 & 1.09 (0.66 to 1.80$)$ \\
\hline Others & $387192(9.17)$ & $570(6.74)$ & 1.47 & $0.58(0.53 \text { to } 0.64)^{*}$ & $36(5.35)$ & 63.16 & 0.95 (0.67 to 1.35$)$ \\
\hline \multicolumn{8}{|l|}{ Major surgical procedure } \\
\hline AAA repair & $1744(0.04)$ & $26(0.31)$ & 14.91 & 1.00 & $6(0.89)$ & 230.77 & 1.00 \\
\hline CABG & $10529(0.25)$ & $52(0.62)$ & 4.94 & $0.37(0.23 \text { to } 0.60)^{*}$ & $7(1.04)$ & 134.62 & 0.69 (0.23 to 2.10$)$ \\
\hline Cholecystectomy & 50145 (1.19) & $42(0.50)$ & 0.84 & $0.09(0.05 \text { to } 0.15)^{*}$ & $6(0.89)$ & 142.86 & 0.70 (0.22 to 2.22$)$ \\
\hline Total hip replacement & $18771(0.44)$ & $207(2.45)$ & 11.03 & 0.74 (0.49 to 1.11$)$ & $4(0.59)$ & 19.32 & $0.12(0.03 \text { to } 0.44)^{*}$ \\
\hline Total knee replacement & $29428(0.70)$ & $798(9.44)$ & 27.12 & $1.76(1.19 \text { to } 2.61)^{*}$ & $3(0.45)$ & 3.76 & $0.03(0.01 \text { to } 0.11)^{*}$ \\
\hline Other & $4112700(97.38)$ & 7326 (86.69) & 1.78 & $0.17(0.11 \text { to } 0.24)^{*}$ & $647(96.14)$ & 88.32 & $0.52(0.23$ to 1.19$)$ \\
\hline \multicolumn{8}{|l|}{ Major principle diagnostic diseases $\ddagger$} \\
\hline Cardiac arrhythmias & $25953(0.61)$ & $75(0.89)$ & 2.89 & & & & \\
\hline Chronic pulmonary disease & $11558(0.27)$ & $69(0.82)$ & 5.97 & & & & \\
\hline Coagulopathy & $3908(0.09)$ & $37(0.44)$ & 9.47 & & & & \\
\hline Congestive heart failure & $6765(0.16)$ & $85(1.01)$ & 12.56 & & & & \\
\hline Diabetes with chronic complication & $33541(0.79)$ & $79(0.93)$ & 2.36 & - & $2(0.30)$ & 26.67 & \\
\hline $\begin{array}{l}\text { Malignancy including lymphoma } \\
\text { and leukaemia }\end{array}$ & $150962(3.57)$ & $1070(12.66)$ & 7.09 & - & $6(0.89)$ & 86.96 & \\
\hline Metastatic solid tumour & $19699(0.47)$ & $291(3.44)$ & 14.77 & - & $2(0.30)$ & 54.05 & - \\
\hline Peripheral vascular disease & $15993(0.38)$ & $141(1.67)$ & 8.82 & - & $17(2.53)$ & 200.00 & - \\
\hline Renal failure & $1385753(32.81)$ & $42(0.50)$ & 0.03 & - & $11(1.63)$ & 139.24 & - \\
\hline $\begin{array}{l}\text { Rheumatoid arthritis/collagen } \\
\text { vascular disease }\end{array}$ & $10748(0.25)$ & $40(0.47)$ & 3.72 & - & $182(27.04)$ & 170.09 & - \\
\hline Year & & & & - & $67(9.96)$ & 230.24 & - \\
\hline 2002 & $431184(10.21)$ & $763(9.03)$ & 1.77 & - & $10(1.49)$ & 70.92 & - \\
\hline 2003 & 438058 (10.37) & $780(9.23)$ & 1.78 & - & $1(0.15)$ & 23.81 & - \\
\hline
\end{tabular}




\begin{tabular}{|c|c|c|c|c|c|c|c|}
\hline \multirow[b]{2}{*}{ Characteristics } & \multirow{2}{*}{$\begin{array}{l}\text { Surgical } \\
\text { patients n (\%) }\end{array}$} & \multicolumn{3}{|l|}{ VTE } & \multicolumn{3}{|c|}{ VTE-associated death } \\
\hline & & Frequency (\%) & IR & IRR (95\% Cl) & Frequency (\%) & IR & IRR (95\% Cl) \\
\hline 2004 & 462451 (10.95) & $878(10.39)$ & 1.90 & - & $1(0.15)$ & 25.00 & - \\
\hline 2005 & 508097 (12.03) & $1038(12.28)$ & 2.04 & $1.17(1.07 \text { to } 1.29)^{*}$ & $75(11.14)$ & 72.25 & - \\
\hline 2006 & 550688 (13.04) & $1062(12.57)$ & 1.93 & $1.11(1.01$ to 1.22$) \dagger$ & $103(15.30)$ & 96.99 & - \\
\hline 2007 & 591973 (14.02) & $1223(14.47)$ & 2.07 & $1.22(1.12 \text { to } 1.34)^{\star}$ & $87(12.93)$ & 71.14 & $0.72(0.52$ to 1.01$)$ \\
\hline 2008 & 607631 (14.39) & $1313(15.54)$ & 2.16 & $1.27(1.16 \text { to } 1.38)^{\star}$ & $112(16.64)$ & 85.30 & $0.90(0.66$ to 1.23$)$ \\
\hline 2009 & 633235 (14.99) & 1394 (16.50) & 2.20 & $1.30(1.19 \text { to } 1.42)^{\star}$ & 113 (16.79) & 81.06 & 0.83 (0.60 to 1.13$)$ \\
\hline Year-linear trend & - & - & - & $1.04(1.03 \text { to } 1.05)^{\star}$ & - & - & $0.98(0.95$ to 1.02$)$ \\
\hline \multicolumn{8}{|l|}{ Quartiles of SEIFA } \\
\hline 1st quartile (most disadvantaged) & $1089833(25.81)$ & $2308(27.31)$ & 2.12 & 1.00 & 187 (27.79) & 81.02 & 1.00 \\
\hline 2nd quartile & 1084727 (25.68) & $1981(23.44)$ & 1.83 & $0.88(0.82 \text { to } 0.94)^{\star}$ & $169(25.11)$ & 85.31 & $0.96(0.78$ to 1.20$)$ \\
\hline 3rd quartile & $1074283(25.44)$ & $2088(24.71)$ & 1.94 & $0.76(0.72 \text { to } 0.81)^{*}$ & $175(26.00)$ & 83.81 & $1.04(0.84$ to 1.30$)$ \\
\hline 4th quartile (most advantaged) & $974474(23.07)$ & $2074(24.54)$ & 2.13 & $0.70(0.65 \text { to } 0.75)^{\star}$ & $142(21.10)$ & 68.47 & $0.98(0.77$ to 1.26$)$ \\
\hline \multicolumn{8}{|l|}{ Peer hospital groups } \\
\hline Principal referral & 2269392 (53.73) & $5141(60.83)$ & 2.27 & 1.00 & $381(56.61)$ & 74.11 & 1.00 \\
\hline Ungrouped acute & $133465(3.16)$ & $380(4.50)$ & 2.85 & $1.20(0.54$ to 2.66$)$ & $43(6.39)$ & 113.16 & 0.94 (0.37 to 2.39$)$ \\
\hline $\begin{array}{l}\text { Major metrometropolitan and } \\
\text { non-metropolitan }\end{array}$ & $1140036(26.99)$ & $2125(25.14)$ & 1.86 & $0.84(0.54$ to 1.31$)$ & $183(27.19)$ & 86.12 & 0.96 (0.60 to 1.55$)$ \\
\hline District group 1 & $346910(8.21)$ & $484(5.73)$ & 1.40 & $0.56(0.33$ to 0.95$) \dagger$ & $42(6.24)$ & 86.78 & 0.99 (0.54 to 1.83$)$ \\
\hline District group 2 & $333514(7.90)$ & $321(3.80)$ & 0.96 & $0.37(0.23 \text { to } 0.61)^{\star}$ & $24(3.57)$ & 74.77 & $0.74(0.38$ to 1.44$)$ \\
\hline \multicolumn{8}{|l|}{ Local health district } \\
\hline Metropolitan & $2720690(64.42)$ & $5882(69.60)$ & 2.16 & 1.00 & $430(63.89)$ & 73.10 & 1.00 \\
\hline Rural and Regional NSW & 1502627 (35.58) & $2569(30.40)$ & 1.71 & 0.74 (0.52 to 1.05$)$ & $243(36.11)$ & 94.59 & $1.26(0.82$ to 1.92$)$ \\
\hline Total & 4223317 & 8451 & 2.00 & - & 673 & 79.64 & - \\
\hline
\end{tabular}

139307 (3.2\%) cases were excluded due to missing or unknown items.

IR are crude and reported per 1000 patients.

IRR and related $\mathrm{Cl}$ were obtained using a Poisson mixed model.

*Significant at $1 \%$.

†Significant at $5 \%$.

¥No RR is reported since this characteristic has not been included in the Poisson mixed model.

AAA repair, abdominal aortic aneurysm repair; CABG, coronary artery bypass graft; CI, confidence interval; IR, Incidence rates; IRR, incidence rate ratios; NSW, New South Wales; SEIFA,

Socio-Economic Indices for Areas; VTE, venous thromboembolism. 


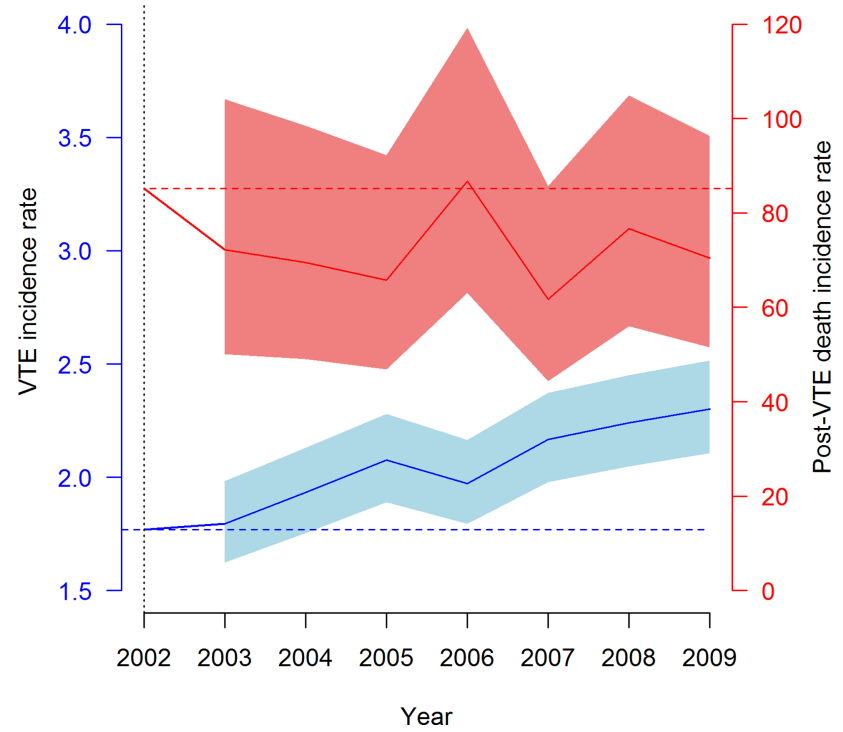

Figure 1 Adjusted trends of postoperative venous thromboembolism (VTE) and post-VTE death incidence rates (per 1000 elective surgical patients and 1000 patients with postoperative VTE, respectively) over the study period. Rates were estimated by multiplying incidence rate ratio (obtained from the Poisson mix model) and crude risk at the reference year (2002).

mortality to be $8 \%$. The adjusted incidence of VTE increased significantly over the study period $(30 \%)$, with no change in mortality. There were significant differences in incidence of VTE between hospital peer groups and between hospitals with the lowest and those with the highest rates. Principal referral hospitals exhibited a higher overall incidence, but lower intragroup variation compared to other peer groups. Principal referral hospitals with a higher incidence of VTE also tended to have a lower VTE-related mortality.
The incidence of postoperative VTE in NSW hospitals was less than half that of US hospitals within a similar period (4.5 or more per 1000 patients in 2010 and prior), ${ }^{25}{ }^{44}$ but with a similar VTE-associated mortality (83 vs $79 / 1000$ patients). ${ }^{25}$ Based on our findings, VTE incidence and associated mortality contributes to approximately $15 \%$ and $8 \%$ of overall FTR-related incidence and mortality (13.8 and 140 per 1000 patients, respectively). ${ }^{4546}$ Despite the fact that our study and the US study used the identical measure defined by $\mathrm{AHRQ}^{23}$ the discrepancies and coding practices between the USA (ICD-9-CM) and Australia (ICD-10-AM) may, in part, have contributed to the difference. It was shown that accuracy of VTE coding can be improved by the adoption of extended codes developed in the revised ICD-9-CM. ${ }^{47}$

In a recent Organization for Economic and Co-Operation and Development (OECD) report, Australia-wide incidence were 0.97 and 1.26/1000 patients in 2009 and 2012 respectively, placing Australia among three nations (Australia, Slovenia and the USA) with the highest incidence of approximately 1 per a 1000 surgical patients or more within the last decade. ${ }^{48}$ Our observed rates for NSW hospitals was nearly double that of the OCED provided Australian rates, possibly due to the fact that we studied only elective surgical patients from acute public hospitals. Such cross-nations' reports provide a platform for health service comparisons and the study of longitudinal variations. However, internal and external comparability of OCED results may be affected by the heterogeneity and biases of the different nations' coding systems.

Despite continued poor compliance with VTE prevention guidelines and VTE preventative measures, ${ }^{49-52}$ postoperative VTE incidence in US hospitals almost halved between 2007 and 2011. ${ }^{24} 44$ In Australia, given the overt gap between evidence and practice of VTE
Figure 2 Hospital peer group-specific adjusted trends of postoperative venous thromboembolism (VTE) (left panel) and post-VTE death (right panel) incidence rates (per 1000 elective surgical patients and 1000 patients with postoperative VTE, respectively) over the study period. Rates were estimated by multiplying incidence rate ratio (obtained from the Poisson mix model including an interaction term for 'hospital peer groupxyear') and crude risk of the reference hospital group (principal referral) at the reference year (2002).

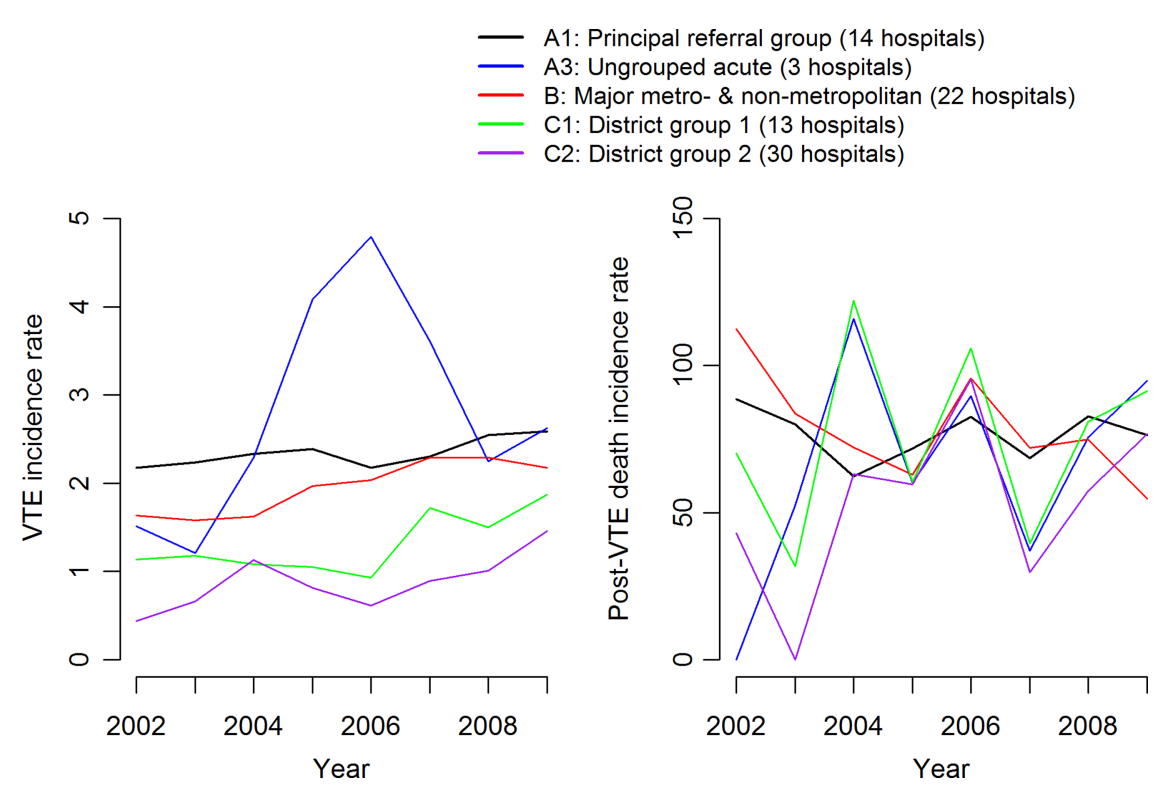



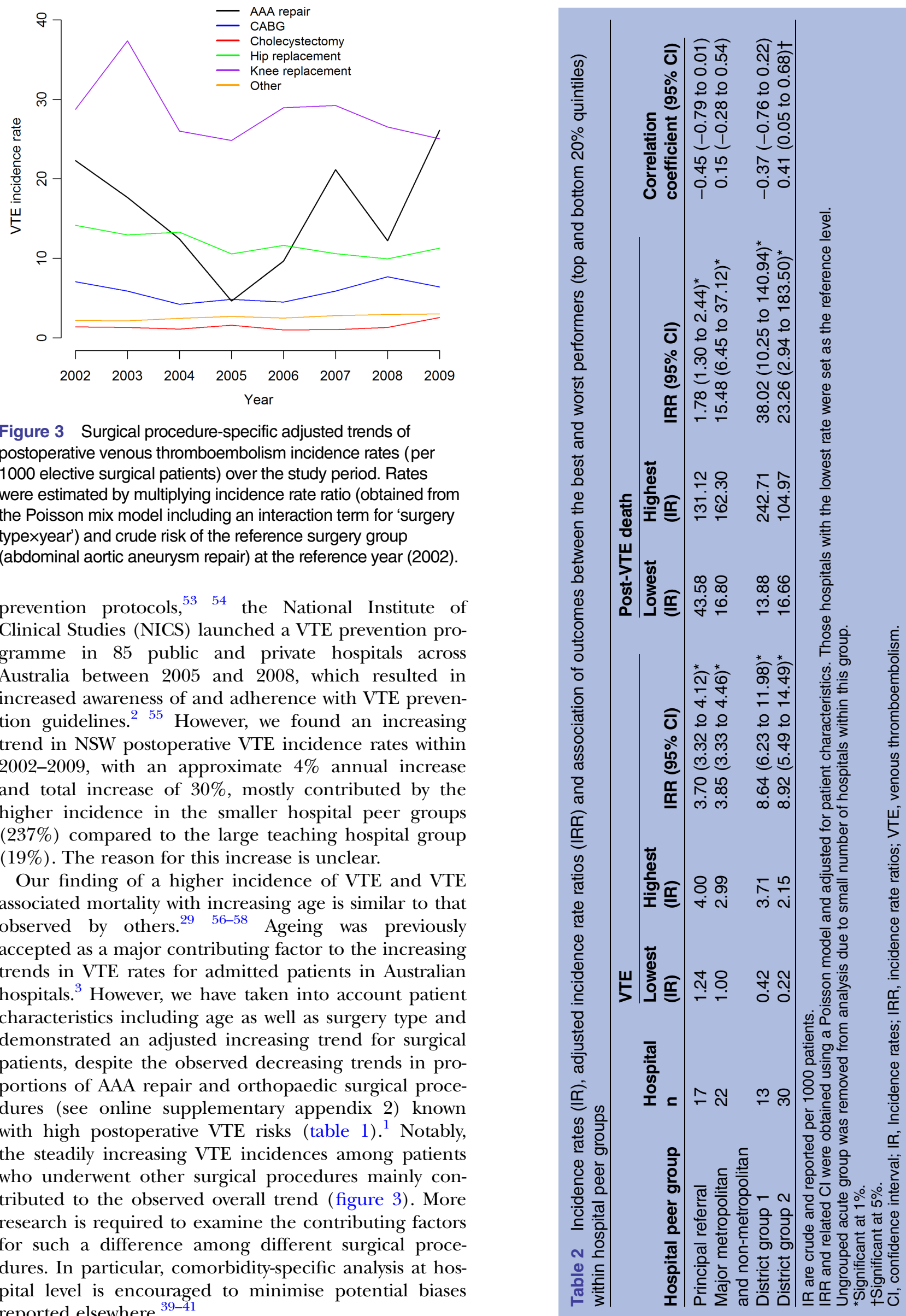

Figure 3 Surgical procedure-specific adjusted trends of postoperative venous thromboembolism incidence rates (per 1000 elective surgical patients) over the study period. Rates were estimated by multiplying incidence rate ratio (obtained from the Poisson mix model including an interaction term for 'surgery typexyear') and crude risk of the reference surgery group (abdominal aortic aneurysm repair) at the reference year (2002).

prevention protocols, ${ }^{53} 54$ the National Institute of Clinical Studies (NICS) launched a VTE prevention programme in 85 public and private hospitals across Australia between 2005 and 2008, which resulted in increased awareness of and adherence with VTE prevention guidelines. ${ }^{2}{ }^{55}$ However, we found an increasing trend in NSW postoperative VTE incidence rates within 2002-2009, with an approximate 4\% annual increase and total increase of $30 \%$, mostly contributed by the higher incidence in the smaller hospital peer groups (237\%) compared to the large teaching hospital group $(19 \%)$. The reason for this increase is unclear.

Our finding of a higher incidence of VTE and VTE associated mortality with increasing age is similar to that observed by others. ${ }^{29}$ 56-58 Ageing was previously accepted as a major contributing factor to the increasing trends in VTE rates for admitted patients in Australian hospitals. ${ }^{3}$ However, we have taken into account patient characteristics including age as well as surgery type and demonstrated an adjusted increasing trend for surgical patients, despite the observed decreasing trends in proportions of AAA repair and orthopaedic surgical procedures (see online supplementary appendix 2) known with high postoperative VTE risks (table 1). Notably, the steadily increasing VTE incidences among patients who underwent other surgical procedures mainly contributed to the observed overall trend (figure 3). More research is required to examine the contributing factors for such a difference among different surgical procedures. In particular, comorbidity-specific analysis at hospital level is encouraged to minimise potential biases reported elsewhere. ${ }^{39-41}$ 
Although other studies suggest gender may not be a significant risk factor for VTE, ${ }^{28}{ }_{29}^{59}$ we found men were less likely to develop VTE complications, but more likely to subsequently die. We did not separately explore DVT and PE incidence and associated deaths between genders; but our higher mortality risk for men can be explained by the estimated higher odds of PE (vs DVT, which has a lower risk of death ${ }^{29} 59$ for men compared to women ( 1.87 vs 1.02 respectively) in Australian hospitals during our study period. ${ }^{3}$

Variation in the application of VTE prevention guidelines and other quality initiatives may have contributed to the differences in outcomes among the hospitals in our study. Smaller district 1 and 2 peer group hospitals had a significantly lower VTE incidence rate compared to larger hospitals in NSW. This was in contrast with other studies, which showed that larger hospitals have a lower mortality following major procedures, such as orthopaedic surgeries $^{60}{ }^{61}$ and postoperative complications such as VTE. ${ }^{62}$ A possible explanation for this discrepancy is that principal referral hospitals undertook higher risk patients and surgical complexity than the smaller district hospitals. Geographical variations in coding, ${ }^{39-41}$ underreporting of VTE due to mis-coding to a more general cardiovascular item $^{363}$ and high diagnosis likelihood of high risk but asymptomatic postoperative patients ${ }^{64}$ may also have contributed to elevated VTE rates in major hospitals. We did not observe any differences between NSW hospital peer groups for VTE mortality, neither other studies did for FTR rates. ${ }^{45}$ However, we did observe greater variation in VTE mortality within peer groups comprising smaller sized hospitals in comparison to larger principal referral hospitals.

Our study showed a significant performance difference between hospitals and within each hospital peer group of the highest and the lowest VTE incidence and associated mortality. Similarly, the association between the two outcomes also varied across groups. Smaller hospitals (district groups 1 and 2) exhibited larger differences in both outcomes, suggesting a greater variability of patient care practice and outcomes among this group of hospitals and the greater potential for intervention aimed at VTE prevention and treatment for this group. We also noted a positive association between VTE incidence and VTE mortality among smaller size hospital groups. In contrast, the fact that larger NSW hospitals tended to have a higher VTE incidence but lower VTE associated mortality suggests that there may be a volume-outcome relationship or a greater adherence to evidence-based prevention and treatment guidelines, which may explain this better VTE-associated mortality. Interestingly, if the higher incidence of VTE alone was used as a measure of failure-to-prevent, these hospitals may be considered to have performed poorly overall, despite the better VTE-associated mortality. Conversely, if the higher incidence rates of VTE were largely due to patient selection and case-mix, these hospitals could be considered as better quality hospitals having a lower FTR rate with better treatment outcomes. Further investigation into the factors that may explain these differences and the ideal reporting measures is warranted.

Our study raised several important policy implications. First, despite the fact that national and state agencies had developed evidence-based guidelines, such as the Clinical Excellence Commission of NSW 'Medication Safety, ${ }^{65}$ in which VTE prevention practices were promoted and related incidents evaluated, the increasing incidence of VTE and unchanged VTE mortality question the effectiveness of current national policy and local programmes in reducing VTE incidence and mortality. Second, the development of a systematic local programme based on relevant international experience in successfully reducing VTE rate and its related mortality needs urgent policy action. Third, the large variability of VTE rate and its related mortality between and within different hospital peer groups suggests that there is room for improvement in the prevention and also in the treatment of VTE and that VTE still remains a preventable complication. Lastly, as an important indicator of the quality of care, the level of standardised reporting of VTE in Australia should be explored.

The strengths of our study are that it is the first population-based observational study across all acute public hospitals within one (ie, NSW) health region. We used a standardised measure and presented incidence rates of VTE and VTE-associated mortality as well, thus enabling differentiation between the two outcome measures and allowing for international comparisons. Limitations of our study include that we specifically studied only elective surgical patients according to AHRQ definitions; whereas the analyses of all patient populations may provide addition insight. Future research needs to provide more evidence on the whole inpatient population. We also may have under-reported our findings because of possible coding discrepancies. Nevertheless, this study reinforced the importance of developing measures for combating postoperative VTE, and the continual monitoring and public reporting of VTE incidence and mortality. ${ }^{266}$

\section{CONCLUSION}

The significant increase in VTE incidence among surgical patients over an 8-year period and persisting level of VTE-associated mortality highlights the need for urgent policy interventions. The significant variation for both outcomes between, and within, different hospital peer groups suggests room for improvement in the prevention and also treatment of VTE. Routine measurement and disclosure of VTE incidence as well as associated mortality can provide policymakers, clinicians and researchers with opportunities to monitor and adjust for performance.

\section{Author affiliations}

${ }^{1}$ Simpson Centre for Health Services Research, South Western Sydney Clinical School \& Australian Institute of Health Innovation, University of New South Wales, Sydney, New South Wales, Australia

${ }^{2}$ Epidemiology, Western Sydney Local Health District, Sydney, New South Wales, Australia 
${ }^{3}$ Intensive Care Unit, Royal Adelaide Hospital \& Faculty of Health Sciences, University of Adelaide, Adelaide, South Australia, Australia

Contributors $\mathrm{HA}, \mathrm{JC}, \mathrm{AF}$ and $\mathrm{KH}$ conceived and designed the study. $\mathrm{HA}, \mathrm{JC}$ and $\mathrm{LO}$ prepared the data and performed the analyses. $\mathrm{HA}, \mathrm{JC}, \mathrm{SJH}, \mathrm{AF}$ and $\mathrm{KH}$ wrote the paper.

Funding This work was partly supported by two National Health and Medical Research Council Project grants, Australia (APP1009916 and APP1020660). The funders had no role in study design, data collection and analysis, decision to publish or preparation of the manuscript.

Competing interests None.

Ethics approval Ethical approval was obtained from the University of NSW Human Research Ethics Committee (LNR/11/CIPHS/64).

Provenance and peer review Not commissioned; externally peer reviewed.

Data sharing statement No additional data are available.

Open Access This is an Open Access article distributed in accordance with the Creative Commons Attribution Non Commercial (CC BY-NC 4.0) license, which permits others to distribute, remix, adapt, build upon this work noncommercially, and license their derivative works on different terms, provided the original work is properly cited and the use is non-commercial. See: http:// creativecommons.org/licenses/by-nc/4.0/

\section{REFERENCES}

1. Geerts WH, Bergqvist D, Pineo GF, et al. Prevention of venous thromboembolism: American College of Chest Physicians Evidence-Based Clinical Practice Guidelines (8th Edition). Chest 2008:133:381S-453S

2. National Health and Medical Research Council. Preventing venous thromboembolism in hospitalised patients: summary of NHMRC activity 2003-2010. Melbourne: NHMRC, 2011.

3. Access Economics. The burden of venous thromboembolism in Australia. Report for the Australia and New Zealand working party on the management and prevention of venous thromboembolism, 2008.

4. Mahan CE, Holdsworth MT, Welch SM, et al. Deep-vein thrombosis: a United States cost model for a preventable and costly adverse event. Thromb Haemost 2011;106:405-15.

5. Centers for Disease Control and Prevention. Venous thromboembolism in adult hospitalizations-United States, 20072009. MMWR Morb Mortal Wkly Rep 2012:401-04.

6. Galson SK. The surgeon generals call to action to prevent deep vein thrombosis and pulmonary embolism. US Department of Health and Human Services, 2009

7. Chong $\mathrm{BH}$, Braithwaite $\mathrm{J}$, Harris MF, et al. Venous thromboembolism - a major health and financial burden: how can we do better to prevent this disease? Med J Aust 2008;189:134-5.

8. Ho WK, Hankey GJ, Eikelboom JW. The incidence of venous thromboembolism: a prospective, community-based study in Perth, Western Australia. Med J Aust 2008;189:144-7.

9. The Joint Commission. Performance measurement initiativesnational consensus standards for prevention and care of venous thromboembolism (VTE), 2007.

10. Sandler DA, Martin JF. Autopsy proven pulmonary embolism in hospital patients: are we detecting enough deep vein thrombosis? J R Soc Med 1989;82:203.

11. Michota FA. Bridging the gap between evidence and practice in venous thromboembolism prophylaxis: the quality improvement process. J Gen Intern Med 2007;22:1762-70.

12. Guyatt GH, AkI EA, Crowther M, et al. American College of Chest Physicians Antithrombotic Therapy and Prevention of Thrombosis Panel. Executive summary: Antithrombotic Therapy and Prevention of Thrombosis 9th ed: American College of Chest Physicians Evidence-Based Clinical Practice Guidelines. Chest 2012;141:7S-47S

13. Lau BD, Haut ER. Practices to prevent venous thromboembolism: a brief review. BMJ Qual Saf 2014;23:187-95.

14. O'Donnell M, Weitz JI. Thromboprophylaxis in surgical patients. Can J Surg 2003;46:129.

15. White RH, Zhou H, Romano PS. Incidence of symptomatic venous thromboembolism after different elective or urgent surgical procedures. Thromb Haemost 2003;90:446-55.

16. Agnelli G. Prevention of venous thromboembolism in surgical patients. Circulation 2004;110:IV4-12.
17. Kahn SR, Morrison DR, Cohen JM, et al. Interventions for implementation of thromboprophylaxis in hospitalized medical and surgical patients at risk for venous thromboembolism. Cochrane Database Syst Rev 2013;7:CD008201. doi:10.1002/14651858. CD00820

18. Stevens SM, Douketis JD. Deep vein thrombosis prophylaxis in hospitalized medical patients: current recommendations, general rates of implementation, and initiatives for improvement. Clin Chest Med 2010;31:675-89.

19. Amin AN, Lin J, Thompson S, et al. Real-world rates of in-hospital and postdischarge deep-vein thrombosis and pulmonary embolism in at-risk medical patients in the United States. Clin Appl Thromb Hemost 2011;17:611-19.

20. National Health and Medical Research Council. Clinical practice guideline for the prevention of venous thromboembolism (deep vein thrombosis and pulmonary embolism) in patients admitted to Australian hospitals. Melbourne: National Health and Medical Research Council, 2009.

21. The Joint Commission. Specifications manual for national hospital quality measures, 2009.

22. Centers for Medicare and Medicaid Services. Hospital value-based purchasing (HVBP) program. Secondary Hospital value-based purchasing (HVBP) program 2013. http://www.cms.gov/Medicare/ Quality-Initiatives-Patient-Assessment-Instruments/ hospital-value-based-purchasing/index.html

23. Agency for Healthcare Research and Quality. AHRQ quality indicators: patient safety indicators: technical specifications (Version 4.1). Agency for Healthcare Research and Quality, 2009.

24. HealthGrades. Variation in patient safety outcomes and the importance of being informed. US: HealthGrades, 2013.

25. Reed K, May R. HealthGrades patient safety in American hospitals study. US: HealthGrades, 2011

26. Semel ME, Lipsitz SR, Funk LM, et al. Rates and patterns of death after surgery in the United States, 1996 and 2006. Surgery 2012;151:171-82.

27. The Joint Commission. Improving America's hospitals. The Joint Commission's Annual Report on Quality and Safety, 2013.

28. Anderson Jr FA, Spencer FA. Risk factors for venous thromboembolism. Circulation 2003;107:19-16.

29. Naess IA, Christiansen SC, Romundstad P, et al. Incidence and mortality of venous thrombosis: a population-based study. J Thromb Haemost 2007;5:692-9.

30. Raffini L, Trimarchi T, Beliveau J, et al. Thromboprophylaxis in a pediatric hospital: a patient-safety and quality-improvement initiative. Pediatrics 2011;127:e1326-32.

31. Sliwka D, Fang MC. Venous thromboembolism prophylaxis in the United States: still room for improvement. J Gen Intern Med 2010;25:484-6.

32. Australian Institute of Health and Welfare (AIHW). VTE related hospitalisations in Australia: national hospital morbidity data 19992008. AlHW, 2010.

33. National Centre for Classification in Health N. The International Statistical Classification of Diseases and Related Health Problems, Tenth Revision, Australian Modification (ICD-10-AM). Sydney: $\mathrm{NCCH}$, Faculty of Health Sciences, The University of Sydney, 2004.

34. Victorian Government Health Information. Patient safety indicators-translated technical specifications. Melbourne: Victorian State Government, Department of Health, 2006.

35. McConchie S, Shepheard J, Waters S, et al. The AusPSIs: the Australian version of the Agency of Healthcare Research and Quality patient safety indicators. Aust Health Rev 2009;33:334-50.

36. Australian Bureau of Statistics. Census of population and housing Socio-Economic Indexes for Areas (SEIFA), Australia. Canberra: Australian Bureau of Statistics, 2011.

37. Quan $\mathrm{H}$, Sundararajan V, Halfon $\mathrm{P}$, et al. Coding algorithms for defining comorbidities in ICD-9-CM and ICD-10 administrative data Med Care 2005;43:1130-9.

38. NSW Health. NSW health services comparison data book 2008/ 2009. Sydney: NSW Health, 2010.

39. Song Y, Skinner J, Bynum J, et al. Regional variations in diagnostic practices. N Engl J Med 2010;363:45-53.

40. Welch HG, Sharp SM, Gottlieb DJ, et al. Geographic variation in diagnosis frequency and risk of death among Medicare beneficiaries. JAMA 2011;305:1113-18.

41. Wennberg JE, Staiger DO, Sharp SM, et al. Observational intensity bias associated with illness adjustment: cross sectional analysis of insurance claims. BMJ 2013;346:f549.

42. R Development Core Team. R: A Language and Environment for Statistical Computing [program]. Vienna, Austria: R Foundation Statistical Computing, 2013. 
43. Stata Statistical Software: Release 11 [program]. College Station, TX: StataCorp LP, 2009.

44. Agency for Healthcare Research and Quality (AHRQ). Patient safety indicator v4.5 benchmark data tables, 2013.

45. Ou L, Chen J, Assareh $\mathrm{H}$, et al. Trends and variations in the rates of hospital complications, failure-to-rescue and 30-day mortality in surgical patients in New South Wales, Australia, 2002-2009. PLoS ONE 2014;9:e96164.

46. Ou L, Chen J, Assareh $\mathrm{H}$, et al. Rate of Failure to Rescue in Public Acute Hospitals in NSW 2002-2009. Ingham Institute 8th Annual Research \& Teaching Showcase. Sydney: Ingham Institute, 2013:10-11.

47. Sadeghi B, White RH, Maynard G, et al. Improved coding of postoperative deep vein thrombosis and pulmonary embolism in administrative data (AHRQ patient safety indicator 12) after introduction of new ICD-9-CM diagnosis codes. Med Care 2013;4. Published online, doi:10.1097/MLR.0b013e318287d59e

48. The Organisation for Economic Co-operation and Development (OECD). OECD health statistics. Secondary OECD health statistics 2013. http://www.oecd.org/els/health-systems/oecdhealthdata.htm

49. Wakefield TW, McLafferty RB, Lohr JM, et al. Call to action to prevent venous thromboembolism. J Vasc Surg 2009;49:1620-3.

50. Goldhaber SZ, Tapson VF. A prospective registry of 5,451 patients with ultrasound-confirmed deep vein thrombosis. Am J Cardiol 2004:93:259-62.

51. Cohen AT, Tapson VF, Bergmann JF, et al. Venous thromboembolism risk and prophylaxis in the acute hospital care setting (ENDORSE study): a multinational cross-sectional study. Lancet 2008;371:387-94.

52. Schaden E, Metnitz PG, Pfanner G, et al. Coagulation day 2010: an Austrian survey on the routine of thromboprophylaxis in intensive care. Intensive Care Med 2012;38:984-90.

53. National Institute of Clinical Studies (NICS). The incidence and risk factors for venous thromboembolism in hospitals in Western Australia 1999-2001. Prepared by School of Population Health, University of Western Australia. Melbourne: NICS, 2005.

54. National Institute of Clinical Studies (NICS). Evidence-practice gaps report. Melbourne: NICS, 2003.
55. National Institute of Clinical Studies (NICS). Evidence practice gaps report-Volume 1. A review of developments 2004-2007. Melbourne: NICS, 2008.

56. Heit JA, O'Fallon WM, Petterson TM, et al. Relative impact of risk factors for deep vein thrombosis and pulmonary embolism: a population-based study. Arch Intern Med 2002:162:1245.

57. Anderson FA Jr, Wheeler HB, Goldberg RJ, et al. A population-based perspective of the hospital incidence and case-fatality rates of deep vein thrombosis and pulmonary embolism: the Worcester DVT Study. Arch Intern Med 1991;151:933.

58. Huo MH, Spyropoulos AC. The eighth American college of chest physicians guidelines on venous thromboembolism prevention: implications for hospital prophylaxis strategies. J Thromb Thrombolysis 2011;31:196-208.

59. White RH. The epidemiology of venous thromboembolism. Circulation 2003;107:14-8.

60. Taylor HD, Dennis DA, Crane HS. Relationship between mortality rates and hospital patient volume for medicare patients undergoing major orthopaedic surgery of the hip, knee, spine, and femur. $J$ Arthroplasty 1997;12:235-42.

61. Katz JN, Barrett J, Mahomed NN, et al. Association between hospital and surgeon procedure volume and the outcomes of total knee replacement. J Bone Joint Surg 2004;86:1909-16.

62. Ghaferi AA, Birkmeyer JD, Dimick JB. Hospital volume and failure to rescue with high-risk surgery. Med Care 2011;49:1076-81.

63. Millar J, Mattke S. Members of the OECD Patient Safety Panel. Selecting indicators for patient safety at the health systems level in OECD countries. OECD Health Technical Papers. France, 2004.

64. Vartak S, Ward MM, Vaughn TE. Do postoperative complications vary by hospital teaching status? Med Care 2008;46:25-32.

65. NSW TAG and Clinical Excellence Commission. Indicators for Quality Use of Medicines in Australian Hospitals. Sydney: NSW Therapeutic Advisory Group, 2007.

66. Chen J. Public reporting of health system performance: a rapid review of evidence on impact on patients, providers and healthcare organisations. Sydney: Sax Institute, 2010. 